\title{
BMJ Open Effect of age and cone dimensions on cervical regeneration: an Italian multicentric prospective observational study
}

\author{
Andrea Ciavattini, ${ }^{1}$ Giovanni Delli Carpini, ${ }^{1}$ Lorenzo Moriconi, ${ }^{1}$ Nicolò Clemente, ${ }^{1}$ \\ Nina Montik, ${ }^{1}$ Rosa De Vincenzo, ${ }^{2}$ Anna Del Fabro, ${ }^{3}$ Monica Buttignol, ${ }^{3}$ \\ Caterina Ricci, ${ }^{2}$ Francesca Moro, ${ }^{2}$ Francesco Sopracordevole ${ }^{3}$
}

To cite: Ciavattini A, Delli Carpini G, Moriconi L, et al. Effect of age and cone dimensions on cervical regeneration: an Italian multicentric prospective observational study. BMJ Open 2018;8:e020675. doi:10.1136/ bmjopen-2017-020675

- Prepublication history and additional material for this paper are available online. To view these files, please visit the journal online (http://dx.doi org/10.1136/bmjopen-2017020675).

Received 16 November 2017 Revised 12 January 2018 Accepted 5 February 2018

Check for updates

${ }^{1}$ Woman's Health Sciences Department, Università Politecnica delle Marche, Ancona, Italy

${ }^{2}$ Division of Gynecologic Oncology, Department of Obstetrics and Gynecology, Catholic University of the Sacred Heart, Rome, Italy

${ }^{3}$ Gynecological Oncology Unit, Centro di Riferimento Oncologico - National Cancer Institute, Aviano, Italy

Correspondence to Prof. Andrea Ciavattini; ciavattini.a@libero.it

\section{ABSTRACT}

Objectives To evaluate cervical regeneration at 6 months following excisional treatment for high-grade cervical intraepithelial neoplasia (CIN), and to investigate the effect of cone dimensions, age of patients and technique of excision on the efficacy of the regeneration process.

Design Prospective observational multicentric study.

Setting Three tertiary care and research centres.

Participants Among the 197 eligible women of childbearing age, older than 25 years of age, undergoing for the first time a loop electrosurgical excision procedure or carbon dioxide laser cervical excision for a high-grade CIN at the colposcopy-directed cervical punch biopsy, and with a final diagnosis of high-grade CIN, 165 completed the 6-month follow-up and were included in the analysis.

Primary outcome measures The cervical length and volume regeneration (\%) after 6 months from procedure were determined by three-dimensional ultrasound, and the correlation of regeneration with cone dimensions, age and excision technique was evaluated.

Results The mean \pm SD cervical length regeneration at 6 months was $89.5 \% \pm 6.3 \%$ and the mean \pm SD cervical volume regeneration was $86.3 \% \pm 13.2 \%$. At the multivariate analysis, a significant and independent inverse correlation between excised cone length and cervical regeneration emerged $(r=-0.39, P<0.001)$. A significantly negative trend in length regeneration at 6 months from procedure with an increasing class of cone length was found $(P<0.001)$. No significant association was found in relation with patient age at the time of procedure or with the technique of excision.

Conclusions Cervical length regeneration at 6 months from excisional treatments is negatively affected by an increasing cone length but not from the age of the patient or the technique of excision. While still achieving equal clinical efficacy, it is crucial to contain cone dimensions, in order to favour a greater length regeneration, reducing the cervical harm and the potential future obstetric complications.
Strengths and limitations of this study

- This study uses robust methodology, with power calculation performed at the onset of the study, and a large number of patients included in the analysis.

- A small number of patients were lost at follow-up.

- The ultrasounds were performed by three different operators in the three centres, even though the operator was the same for each patient.

\section{INTRODUCTION}

Cervical intraepithelial neoplasia (CIN) is a potential precancerous lesion in the cervical epithelium and, as indicated by the European Guidelines for Quality Assurance in Cervical Cancer Screening and by the guidelines of the American Society for Colposcopy and Cervical Pathology, ${ }^{12}$ a surgical treatment is recommended for women diagnosed with high-grade CIN (CIN2+). Loop electrosurgical excision procedure (LEEP) and carbon dioxide-laser cervical excision $\left(\mathrm{CO}_{2}\right.$ laser $)$ are currently the most common procedures used for cervical excisional treatment. These techniques are usually performed as outpatient procedures under local anaesthesia, and allow a comprehensive histopathological examination of the excised specimen with precise assessment of both the degree of abnormality and the excision margins.

Excisional treatments for the treatment of CIN have been shown to expose patients to an increased risk of subsequent obstetrical morbidity, especially preterm delivery. ${ }^{4}$ The risk of such adverse obstetric outcomes appears to be related to the dimensions of the excised specimen, ${ }^{5}$ with the cone length being of particular importance. It is indeed reported that a cone length of over $15 \mathrm{~mm}$ is associated with a doubling of the risk of both preterm and very preterm births, ${ }^{6}$ while 
other cone dimensions seem instead less correlated with adverse obstetric outcomes. ${ }^{7}$

Even if the exact pathogenetic link between cervical excisional treatments and risk of prematurity has not yet been fully elucidated, the most reliable hypothesis includes an 'anatomo-functional' cervical impairment in the subsequent pregnancy, with decreased cervical length, compromised cervical integrity, decreased mechanical support and higher risk of prematurity. ${ }^{5}$ In fact, cervical length and cervical length measurement in pregnancy are of crucial importance, since it is reported that women with a prior cervical excisional treatment have shorter midtrimester cervical lengths ${ }^{8}$ and patients who are identified as having a short cervix in the midtrimester $(<20 \mathrm{~mm})$ are at increased risk of delivering preterm. ${ }^{9}$ It is also reported that other factors, such as an altered immunological function, modifications in the antimicrobial defences of the vaginal microbiome, human papillomavirus (HPV) infection and the CIN itself may have a further role in determining the risk of prematurity in subsequent pregnancies. ${ }^{510-12}$

After cervical damage (such as an excisional procedure), a regenerative process that originates from epithelial and stromal tissue repair cells has been described in the literature. ${ }^{13}$ The efficacy of this process has an important role, since a good structural and anatomical recovery, with an adequate restoration of cervical length, could reduce the risk of subsequent negative obstetric outcomes. However, the potential influence on the regeneration process of the factors that could lead to a greater cervical damage and destruction of reserve cells, such as increasing cone specimen dimensions, is not yet fully clarified, as well as the effect of the age of the patient at the procedure or of the excision technique.

Cervical regeneration at 6 months after cervical excisional treatment for CIN has been assessed by ultrasound examination ${ }^{14}$; both two-dimensional and three-dimensional (3D) transvaginal ultrasounds are reported to be imaging methods with a high accuracy in evaluating cervical volume and tumour volume. ${ }^{145}$

Thus, the aim of the present study was to evaluate, by 3D transvaginal ultrasound, the regeneration of uterine cervix at 6 months after excisional treatment for highgrade CIN, and to investigate how cone dimensions and the age at the procedure may affect the regeneration process. As secondary objective, we analysed the impact of different excision techniques (LEEP or $\mathrm{CO}_{2}$ laser) on the regeneration process.

\section{METHODS}

A prospective observational multicentric study was conducted on women of childbearing age who underwent cervical excisional treatment for high-grade CIN diagnosed after colposcopy-directed cervical punch biopsy at our institutions, starting from January 2015. Exclusion criteria were: less than 25 years of age, menopausal status, pregnancy, previous cervical treatment, prior permanent sterilisation and evidence of invasive cancer. At inclusion, all eligible patients signed an informed consent granting their permission to ultrasound examination, cervical excision treatment and data collection.

The background characteristics recorded at inclusion from each patient were: age, body mass index (BMI), number of previous pregnancies, parity, tobacco use, oral contraceptives (OC) use and HIV infection or immunodeficiency. We also reported the type of cervical excision (type 1,2 or 3$),{ }^{16}$ the histopathology of the final cone specimen and the status of ectocervical and endocervical cone margins.

All women underwent a 3D transvaginal ultrasound on the day of the procedure to assess baseline (just before cervical excisional treatment) dimensions and volume of the uterine cervix. The ultrasound and the excisions were performed during the proliferative phase of the menstrual cycle. A repeat 3D ultrasound was conducted 6 months after the procedure, with the purpose of evaluating cervical regeneration, during the same phase of the menstrual cycle. The 6-month period was chosen according to previous studies, reporting that the healing process is completed by the sixth postoperative month, with no difference at 1 year after the procedure. ${ }^{1718}$

All ultrasounds were performed by three examiners with more than 10 years' experience in gynaecological ultrasound and in detecting cervical tumour with a 4-9 $\mathrm{MHz}$ 3D transvaginal probe and a Voluson E10 (GE Healthcare, Milwaukee, Wisconsin, USA). The women were examined in the lithotomy position with an empty bladder, with the technique previously described by Papoutsis et al. ${ }^{14}$ In the multiplanar display of the cervix, we measured cervical length in the sagittal view as the straight distance between the internal and the external os. The anteroposterior and the transverse diameter were measured at the midpoint of the cervical length, in the sagittal view and in the transverse view, respectively.

Cervical volume was calculated with the cylinder geometric formula: volume $=3.14 \times[$ (anteroposterior+transverse diameter) $/ 4]^{2} \times$ cervical length. The cylinder geometric formula for volume determination was preferred over specific computerised software in consideration of its greater simplicity and speed of use, and its comparable accuracy. ${ }^{19}$

The sagittal view of the cervix was successively centralised in the 3D sector in order to acquire 3D volume data set. Two 3D volume data sets containing cervix were acquired for each patient and the set with the best tissue contrast resolution and identification of the cervical contour was selected for further processing for each patient.

The excised specimen dimensions, all determined as a single fragment, were measured (in $\mathrm{mm}$ ) with a ruler before fixation in formalin and, according to the 2011 International Federation of Cervical Pathology and Colposcopy Colposcopic Terminology, ${ }^{16}$ were defined as length (distance from the distal to the proximal margin), thickness (distance from the stromal margin to the surface of the excised specimen) and circumference (the 
perimeter of the excised specimen). The volume of the excised cone (in $\mathrm{cm}^{3}$ ) was calculated by the fluid displacement technique based on Archimedes' principle before fixation in formalin. ${ }^{14}$

Length regeneration at 6 months after cervical excisional treatment $(\%)$ was defined as the cervical length at 6 months $\left(\mathrm{L}_{6 \mathrm{mo}}\right)$ minus the cervical length immediately after the procedure (defined as the difference between ultrasound-determined baseline cervical length and cone length, $\left.\mathrm{L}_{0}\right)$ divided by cone length $\left(\mathrm{V}_{\text {cone }}\right) \times 100$, with the following formula: length regeneration $(\%)=\left[\left(\mathrm{L}_{6 \mathrm{mo}}-\right.\right.$ $\left.\left.\mathrm{L}_{0}\right) / \mathrm{L}_{\text {cone }}\right] \times 100$. The same method was used to determine volume regeneration. The percentage of excised length (cone length/baseline cervical length) and the percentage of excised volume (cone volume/baseline cervical volume) were also calculated.

All cervical excisional treatments were performed in an outpatient setting under local anaesthesia and strict colposcopic guidance. LEEPs were performed in two centres (Woman's Health Sciences Department, Università Politecnica delle Marche, Ancona, and Division of Gynecologic Oncology, Department of Obstetrics and Gynaecology, Catholic University of the Sacred Heart, Rome) with 1.5-2.0 cm rounded loops, chosen according to the type of the transformation zone and the area of cervical tissue to remove. Laser excisions were performed in one centre (Gynaecological Oncology Unit, Centro di Riferimento Oncologico-National Cancer Institute, Aviano) with a hand-directed $\mathrm{CO}_{2}$ laser (Sharplan $\mathrm{CO}_{2}-$ Laser System, Laser Ventures, Woodstock, Georgia, USA) with a maximum power output of $40 \mathrm{~W}$, used in continuous mode. The beam spot diameter ranged from 0.5 to $1 \mathrm{~mm}$ with an irradiance ranging from 2500 to $3500 \mathrm{~W} /$ $\mathrm{cm}^{2}$, guided by a micromanipulator.

In order to evaluate the correlation between background characteristics, cone dimensions or excision technique (LEEP or $\mathrm{CO}_{2}$ laser) and length or volume regeneration, we first performed a univariate analysis between length or volume regeneration and age, BMI, number of previous pregnancies, nulliparity, OC use, tobacco use, cone length, cone volume, percentage of excised length, percentage of excised volume, status of endocervical margins and excision technique. All the variables that were significant in the univariate analysis were included in a linear multivariate model.

The relation between cone length and length or volume regeneration was investigated by identifying four classes of the initial study population: 'cone length $1-9 \mathrm{~mm}$ ', 'cone length 10-14 mm', 'cone length $15-19 \mathrm{~mm}$ ' and 'cone length $\geq 20 \mathrm{~mm}$ ', according to pre-existing literature. ${ }^{20}$ The relation between age and length or volume regeneration was also investigated by identifying five classes within the initial study population: 'age 25-29 years', 'age $30-34$ years', 'age $35-39$ years', 'age $40-45$ years' and 'age 45 or more years'. The length or volume regeneration at 6 months of each class of cone length or age at the procedure were determined and compared with the one-way analysis of variance (ANOVA) test with the Tukey-Kramer test as post-hoc test.

The effect of the excision technique was analysed by a univariate analysis comparing the two subgroups (LEEP or $\mathrm{CO}_{2}$ laser) in terms of baseline characteristics, types of cervical excision, histological features and sonographic cervical characteristics. An analysis of covariance (ANCOVA) was subsequently run to determine the effect of LEEP or $\mathrm{CO}_{2}$ laser on cervical length or volume regeneration after controlling for the variables (covariates) that were significant in the univariate analysis.

The sample size was determined considering the volume regeneration as the primary outcome measure; data from previous literature reported a volume regeneration of $71 \%-98 \%^{11} 1518$ with an SD of $20 \%$. Setting a $9 \%$-wide $95 \%$ CI (with alpha $=0.05$ and beta $=0.20$ ) and an estimated dropout rate of $20 \%$, the determined minimum sample size was 197 women. Therefore, we started recruiting eligible women in January 2015, until reaching 197 cases.

Statistical software SPSS V.20 (SPSS, Chicago, Illinois, USA) was used for data analysis. All continuous variables were tested for normality with the D'Agostino-Pearson test. Normally distributed variables were expressed as mean $\pm \mathrm{SD}$, while skewed variables were reported as median and IQR. The t-test or the Mann-Whitney $\mathrm{U}$ test was used for comparison as appropriate. Qualitative variables were expressed as proportions and were compared with $\chi^{2}$ or Fisher's exact test as appropriate. Correlation between continuous, normally distributed variables was determined with Pearson's correlation coefficient, while the Spearman's correlation coefficient was used for comparison between continuous non-normally distributed variables. A $\mathrm{P}<0.05$ was considered statistically significant.

\section{RESULTS}

From January 2015 to February 2017, according to the study inclusion and exclusion criteria, 197 eligible women, diagnosed with high-grade CIN at the colposcopy-directed cervical punch biopsy, underwent cervical excisional treatment (94 LEEP and $103 \mathrm{CO}_{2}$ laser) in our institutions. Of those, $10(5.1 \%)$ were excluded due to histology (three adenocarcinoma in situ and seven microinvasive cervical cancer), and 22 (11.2\%) did not complete the follow-up. Data on the 165 women who completed the follow-up are presented in this paper.

The mean \pm SD age of the study population was $35.4 \pm 7.0$ years and the mean \pm SD BMI was $22.4 \pm 3.7 \mathrm{~kg} / \mathrm{m}^{2}$. The median (IQR) number of previous pregnancies was 1 $(0-2)$, with $76(46.1 \%)$ nulliparous women. Fifty-four (32.7\%) patients reported tobacco use and 45 (27.3\%) OC use. Table 1 reports the types of cervical excisions and the histological features in the entire study cohort. The mean \pm SD cone length was $12.2 \pm 4.3 \mathrm{~mm}$ and the mean \pm SD cone volume was $2.6 \pm 1.9 \mathrm{~cm}^{3}$.

The sonographic cervical characteristics at baseline (before cervical excisional treatment) and at 6 months after 
Table 1 Types of cervical excision and histological features

Study cohort

Characteristic

$(n=165)$

\begin{tabular}{ll}
\hline $\begin{array}{l}\text { Type of cervical excision } \\
\text { Type } 1\end{array}$ & $70(42.4)$ \\
Type 2 & $57(34.6)$ \\
Type 3 & $38(23.0)$ \\
Cone length $(\mathrm{mm})$ & $12.2 \pm 4.3$ \\
Cone volume $\left(\mathrm{cm}^{3}\right)$ & $2.6 \pm 1.9$ \\
Final histology of the cone specimen & \\
Negative & $10(6.1)$ \\
CIN1 & $19(11.5)$ \\
CIN2 & $61(36.9)$ \\
CIN3 & $75(45.5)$ \\
Positive endocervical margin & $26(15.8)$ \\
Positive ectocervical margin & $7(4.2)$ \\
\hline
\end{tabular}

Data are mean \pm SD or $\mathrm{n}(\%)$ as appropriate.

$\mathrm{CIN}$, cervical intraepithelial neoplasia.

procedure are reported in table 2 ; the mean $\pm \mathrm{SD}$ cervical length regeneration was $89.5 \% \pm 6.3 \%$ and the mean \pm SD cervical volume regeneration was $86.3 \% \pm 13.2 \%$. There was no detectable lesion at ultrasound.

No significant association was found between length or volume regeneration and nulliparity $(90.0 \% \pm 6.2 \%$ vs $89.1 \% \pm 6.4 \%, \quad \mathrm{P}=0.3739$ and $86.8 \% \pm 10.2 \% \quad$ vs $85.8 \% \pm 15.4 \%, \quad \mathrm{P}=0.6254$, respectively), $\mathrm{OC}$ use $(90.5 \% \pm 5.2 \%$ vs $89.1 \pm 6.7 \%, \quad \mathrm{P}=0.23$ and $86.6 \% \pm 9.9 \%$ vs $86.1 \% \pm 14.3 \%, \mathrm{P}=0.86$, respectively), tobacco use $(89.0 \% \pm 6.3 \%$ vs $89.8 \pm 6.3 \%, \mathrm{P}=0.46$ and $85.4 \% \pm 17.9 \%$ vs $86.7 \% \pm 10.3 \%, \mathrm{P}=0.58$, respectively), positive endocervical margins $(88.3 \% \pm 7.2 \%$ vs $89.8 \pm 6.1 \%, \mathrm{P}=0.27$ and $87.6 \% \pm 11.0 \%$ vs $86.0 \% \pm 13.6 \%, \mathrm{P}=0.57$, respectively) and technique of excision (LEEP vs $\mathrm{CO}_{2}$ laser: $90.0 \pm 6.0 \%$ vs $89.0 \pm 6.0 \%, \mathrm{P}=0.30$ and $88.3 \% \pm 10.9 \%$ vs $84.5 \% \pm 14.8 \%$, $\mathrm{P}=0.07$, respectively).

At the univariate analysis of continuous variables associated with length or volume regeneration, only cone

\section{Table 2 Sonographic cervical characteristics}

\begin{tabular}{ll} 
Characteristic & $\begin{array}{l}\text { Study cohort } \\
(\mathbf{n}=165)\end{array}$ \\
\hline Baseline cervical length $(\mathrm{mm})$ & $29.7 \pm 7.6$ \\
Baseline cervical volume $\left(\mathrm{cm}^{3}\right)$ & $15.3 \pm 8.4$ \\
Excised length $(\%)$ & $43.5 \pm 17.3$ \\
Excised volume (\%) & $20.2 \pm 16.8$ \\
Cervical length at 6 months $(\mathrm{mm})$ & $28.4 \pm 7.6$ \\
Cervical volume at 6months $\left(\mathrm{cm}^{3}\right)$ & $14.9 \pm 8.3$ \\
Length regeneration $(\%)$ & $89.5 \pm 6.3$ \\
Volume regeneration $(\%)$ & $86.3 \pm 13.2$ \\
\hline
\end{tabular}

Data are mean $\pm S D$ as appropriate. length and the percentage of excised length showed a significant negative correlation with cervical length regeneration (see online supplementary table 1).

Therefore, these two variables were included in the multivariate linear regression: a significant and independent negative correlation with length regeneration emerged only for cone length $(r=-0.39, \mathrm{P}<0.001)$. Online supplementary figure 1 reports the correlation line between cone length and cervical length regeneration in the whole study population.

The length and volume regeneration at 6 months after procedure according to the four classes of cone length are presented in table 3 .

At the one-way ANOVA test, a significantly negative trend in length regeneration at 6 months after procedures with an increasing class of cone length was found $(\mathrm{P}<0.001)$ (figure 1), while no significant difference was found in volume regeneration. In particular, women with a cone length $<15 \mathrm{~mm}$ presented a significant higher length regeneration than women with a cone length $\geq 15 \mathrm{~mm}$ $(90.7 \% \pm 5.9 \%$ vs $86.9 \% \pm 6.5 \%, \mathrm{P}<0.001)$.

No difference emerged instead in cervical length or volume regeneration according to the five classes of age at the procedure (table 4 ).

Of the 165 patients included in the final analysis, 78 were subjected to LEEP and 87 to $\mathrm{CO}_{2}$ laser excision. The comparison between the two subgroups is reported in online supplementary table 2 . At the univariate analysis, there was no difference in terms of length or volume regeneration between the two subgroups $(90.1 \% \pm 6.0 \%$ vs $89.0 \% \pm 6.6 \%, \mathrm{P}=0.27$ and $88.3 \% \pm 10.9 \%$ vs $84.5 \% \pm 14.8 \%$, $\mathrm{P}=0.06$, respectively). A significantly higher cone length, cone volume, percentage of excised length and percentage of excised volume were found in the $\mathrm{CO}_{2}$ laser subgroup; those four characteristics were considered as covariates in the ANCOVA, while length or volume regeneration were considered as dependent variables and the technique of excision as an independent variable. After adjustment for covariates, there was no statistically significant difference in length regeneration or volume regeneration between the two techniques: $\mathrm{F}(1,159)=0.02, \mathrm{P}=0.90$, partial $\eta 2<0.01$ for length regeneration and $\mathrm{F}(1,159)=1.80, \mathrm{P}=0.18$, partial $\eta 2=0.01$ for volume regeneration. In the LEEP subgroup, a significant increase in both cervical length regeneration $(91.4 \% \pm 5.2 \%$ vs $86.0 \% \pm 6.5 \%, \mathrm{P}<0.01)$ and volume regeneration $(91.2 \% \pm 6.8 \%$ vs $79.3 \% \pm 15.8 \%, \mathrm{P}=0.01)$ was found in women with a cone length $<15 \mathrm{~mm}$ in comparison to women with cone length $\geq 15 \mathrm{~mm}$. In the $\mathrm{CO}_{2}$ laser subgroup, women with a cone length $<19 \mathrm{~mm}$ presented a significant higher length regeneration in comparison to women with a cone length $\geq 19 \mathrm{~mm}(89.6 \% \pm 6.3 \%$ vs $82.7 \% \pm 7.3 \%, \mathrm{P}<0.01)$. No difference in volume regeneration was found.

\section{DISCUSSION}

In the present study, we found significant values of cervical regeneration 6 months after excisional treatments for 
Table 3 Cervical length and volume regeneration in relation with the four classes of cone length

\begin{tabular}{lllll} 
Cone length & $\mathbf{n}$ & $\begin{array}{l}\text { Length } \\
\text { regeneration }\end{array}$ & P value & \multicolumn{2}{l}{$\begin{array}{l}\text { Volume } \\
\text { regeneration }\end{array}$} \\
\hline $1-9 \mathrm{~mm}$ & 43 & $91.9 \pm 4.6$ & $<0.001$ & $85.0 \pm 20.4$ \\
$10-14 \mathrm{~mm}$ & 70 & $90.0 \pm 6.4$ & & $90.0 \pm 5.8$ \\
$15-19 \mathrm{~mm}$ & 44 & $88.0 \pm 5.9$ & & $83.0 \pm 12.2$ \\
$\geq 20 \mathrm{~mm}$ & 8 & $80.3 \pm 6.3$ & & $82.2 \pm 12.1$ \\
\hline
\end{tabular}

Data are mean \pm SD as appropriate.

high-grade CIN, with a mean \pm SD length regeneration of $89.5 \% \pm 6.3 \%$ and a mean \pm SD volume regeneration of $86.3 \% \pm 13.2 \%$. A significant and independent association with cone length $(\mathrm{r}=-0.39, \mathrm{P}<0.001$, see online supplementary figure 1), after adjusting for confounders, emerged. More specifically, a negative trend in length regeneration in relation to an increasing class of cone length was observed (table 4). No association was instead found with the age at the procedure or with the technique of cervical excision (LEEP or $\mathrm{CO}_{2}$ laser).

To our knowledge, this is the largest study about cervical regeneration 6 months after excisional treatment for high-grade CIN, and uses robust methodology, with power calculation performed at the onset of the study, and a small number of patients lost at follow-up. Nevertheless, some limitations need to be acknowledged, such as the fact that the ultrasounds were performed by three different operators in the three centres, even though the operator was the same for each patient.
The additional cervical tissue removed during coagulation for haemostasis cannot be quantified and could be a further limit, even if we did not routinely ablate the cervical crater and we moderately used coagulation, only in case of a single bleeding vessel.

Moreover, our study does not consider data on pregnancy outcomes, in particular regarding the risk of prematurity, since very few women in our cohort became pregnant during the observation period.

The results of the present study have good generalisability, since the study population is well representative of the population of non-pregnant women of childbearing age which undergoes cervical excision for high-grade CIN before having finished their reproductive projects, and it was composed of a sufficient number of patients, determined at the onset of the study, with a reduced dropout rate. Moreover, the ultrasound determination of cervical dimensions and the measurement of cone dimensions could be easily performed in common practice. Future

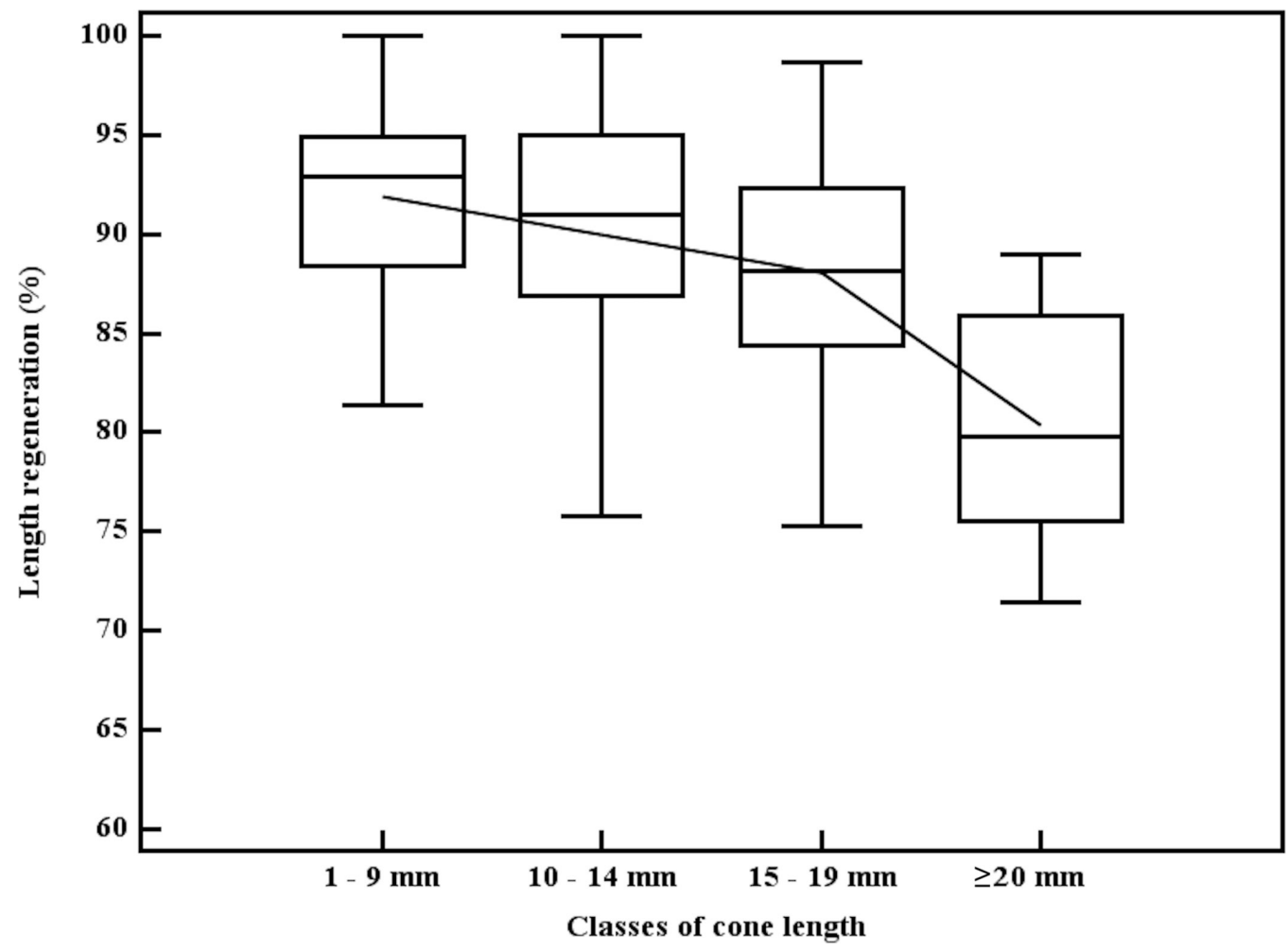

Figure 1 Cervical length regeneration according to the classes of cone length. 
Table 4 Cervical length and volume regeneration in relation with the age at the procedure

\begin{tabular}{lllllll}
\hline Age (years) & $\begin{array}{l}\mathbf{2 5 - 2 9} \\
(\mathbf{n}=\mathbf{3 6})\end{array}$ & $\begin{array}{l}\mathbf{3 0 - 3 4} \\
(\mathbf{n}=\mathbf{4 1})\end{array}$ & $\begin{array}{l}\mathbf{3 5 - 3 9} \\
(\mathbf{n}=\mathbf{4 4})\end{array}$ & $\begin{array}{l}\mathbf{4 0 - 4 4} \\
(\mathbf{n}=\mathbf{3 0})\end{array}$ & $\begin{array}{l}\geq \mathbf{4 5} \\
(\mathbf{n}=\mathbf{1 4})\end{array}$ & P value \\
\hline Length regeneration & $89.6 \pm 6.1$ & $90.1 \pm 5.4$ & $89.6 \pm 6.6$ & $89.1 \pm 7.8$ & $88.0 \pm 5.7$ & 0.864 \\
Volume regeneration & $\mathbf{8 7 . 5} \pm 7.7$ & $89.0 \pm 7.9$ & $83.9 \pm 20.0$ & $84.6 \pm 13.4$ & $86.1 \pm 9.0$ & 0.420 \\
\hline
\end{tabular}

Data are mean \pm SD as appropriate.

studies may also investigate the cervical regeneration pattern in women with previous cervical excision which had been excluded from the present analysis.

Our findings are consistent with the current literature, which reports a cervical length regeneration of $78 \%-94.5 \%$ and a cervical volume regeneration of $81 \%-98 \%$, with a negative correlation with increasing cone dimensions. In particular, Founta et al reported in 2010 that the proportional deficit at 6 months is determined mainly by the proportion of the excised volume, ${ }^{21}$ and Papoutsis et al noted in 2012 that cervical regeneration at 6 months is dependent on the percentage of initial volume excised, with a reduction of $1.37 \%$ for each increase in excised cervical volume of $1 \% .{ }^{14}$ Our data showed a significant inverse correlation between length regeneration and cone length, but not with cone volume or with the percentage of excised volume.

This is the first study reporting the effect of different techniques of excision of cervical regeneration. LEEP and $\mathrm{CO}_{2}$ laser seem to grant similar levels of regeneration, even if cone specimens obtained from $\mathrm{CO}_{2}$ laser procedures presented higher length and volume, as has also been reported by Phadnis et al in 2010. ${ }^{22}$ The inverse correlation between cone length and length regeneration was maintained in both subgroups, while a different cut-off was identified ( $15 \mathrm{~mm}$ vs $19 \mathrm{~mm}$ ). This could mean that $\mathrm{CO}_{2}$ laser could determine good levels of regeneration even for greater cone specimen, up to a cone length of $19 \mathrm{~mm}$.

The regeneration process after cervical excisional treatments seems to originate both from epithelial repair cells (derived from reserve cells of the cervical canal) ${ }^{1323}$ and from stromal repair cells (derived from myofibroblasts). ${ }^{13}$ Thus, it could be argued that an increasing cone length, more than an increasing cone volume, might imply a greater involvement of the cervical canal, with greater destruction of cervical reserve cells ${ }^{23}$ and consequent inability to regenerate and repair properly.

Since the age at the procedure does not seem to significantly affect cervical regeneration, the clinician should be aware that performing a cervical excisional treatment in women of different age seems to grant similar levels of length and volume regeneration, and other factors, such as the colposcopic impression, the extension of lesion, the type of transformation zone and the desire of future pregnancies, should be taken into account, in order to properly tailor the excision and reduce the amount of healthy tissue removed.
The efficacy of the regeneration process after cervical excisional treatment may play a key role in determining the risk of prematurity in the subsequent pregnancies. In fact, it is reported that women with a prior cervical excision have shorter midtrimester cervical lengths ${ }^{8}$ and women who are identified as having a short cervix in the midtrimester $(<20 \mathrm{~mm})$ are at increased risk of delivering preterm. ${ }^{9}$ Although this causal link has not yet been fully clarified, available evidence indicates that cervical excisional treatments are associated with an increased risk of prematurity and perinatal morbidity in a future pregnancy, with a direct relation between the amount of excised tissue and the risk of preterm birth. ${ }^{624-26}$

Thus, considering the importance of the 'anatomo-functional' integrity of the uterine cervix and how it can be affected by cervical excision treatments, an increased cervical recovery decreases cervical impairment and the possibility of future adverse obstetric outcomes.

The study from Castanon et at reported that women with a 'large' cervical excision (length $15-19 \mathrm{~mm}$ ) had a higher risk of preterm delivery than those with smaller excision (absolute risk 2.04, 95\% CI 1.41 to 2.96). In our study, we found the same cut-off of cone length $(\geq 15 \mathrm{~mm})$ for a significantly lower regeneration. Therefore, this association strengthens the conclusion that cervical regeneration after cervical excision could be a significant pathogenetic factor for the risk of prematurity in the subsequent pregnancies.

Although the relation between anatomical impairment caused by cervical excision treatment and adverse obstetric outcomes is supported by current literature, other factors, such as an altered immunological function, modifications in the antimicrobial defences of the vaginal microbiome, HPV infection and the CIN itself may play a key role. ${ }^{5}{ }^{10-12}$ It cannot therefore be excluded that women with high cervical regeneration may still be at risk of prematurity in a future pregnancy.

In conclusion, cervical length regeneration at 6 months after excisional treatment for high-grade CIN seems to be influenced by cone length, with significantly lower levels for an increasing 'class' of cone length, but not from the age of the patient at the procedure or from the technique of excision. Cone dimensions appear therefore to adversely affect both cervical regeneration and the risk of subsequent obstetric outcomes; it is therefore crucial, while still achieving equal clinical efficacy, to perform cervical excisional treatments under colposcopic guidance 
to properly tailor the excision, reducing the amount of healthy tissue removed, and to contain cone dimensions (especially cone length), with the aim of minimising the harm on the cervix and the 'anatomo-functional' impairment, favouring a greater cervical regeneration, with lower risk of future adverse obstetric outcomes.

Ultrasound-determined cervical regeneration and cone length determination could be useful in clinical practice to appropriately counsel women who will undergo cervical excisional treatment for high-grade CIN about the risk of prematurity in a subsequent pregnancy. Women with a history of cervical excisional treatment with greater cone lengths could represent a group of patients in which greater attention needs to be given to prevention and diagnosis of preterm birth in a subsequent pregnancy, potentially due to their lower cervical regeneration.

Contributors AC: project development, data analysis, manuscript revising. GDC: data management, data analysis, manuscript writing. LM: data collection, data analysis, manuscript writing. NC: data collection, data analysis, manuscript writing. NM: data collection, data analysis. RDV: data analysis, manuscript writing. ADF: data collection, data analysis. MB: data management, data collection. CR: data collection, data analysis, manuscript writing. FM: data collection, data analysis, manuscript writing. FS: project development, data analysis, manuscript revising.

Funding This research received no specific grant from any funding agency in the public, commercial or not-for-profit sectors.

Competing interests None declared.

Patient consent Not required.

Ethics approval Local ethics committee approval was properly obtained for the presentstudy (9 June 2014. CR0-2014-08)

Provenance and peer review Not commissioned; externally peer reviewed.

Data sharing statement № additional unpublished data are available.

Open Access This is an Open Access article distributed in accordance with the Creative Commons Attribution Non Commercial (CC BY-NC 4.0) license, which permits others to distribute, remix, adapt, build upon this work non-commercially, and license their derivative works on different terms, provided the original work is properly cited and the use is non-commercial. See: http://creativecommons.org/ licenses/by-nc/4.0/

(c) Article author(s) (or their employer(s) unless otherwise stated in the text of the article) 2018. All rights reserved. No commercial use is permitted unless otherwise expressly granted.

\section{REFERENCES}

1. Arbyn M, Anttila A, Jordan J, et al. European guidelines for quality assurance in cervical cancer screening. Second edition--summary document. Ann Oncol 2010;21:448-58.

2. Massad LS, Einstein MH, Huh WK, et al. 2012 updated consensus guidelines for the management of abnormal cervical cancer screening tests and cancer precursors. J Low Genit Tract Dis 2013;17:S1-S27.

3. Carcopino X, Maycock JA, Mancini J, et al. Image assessment of cervical dimensions after LLETZ: a prospective observational study. BJOG 2013;120:472-8.

4. Kyrgiou M, Athanasiou A, Paraskevaidi M, et al. Adverse obstetric outcomes after local treatment for cervical preinvasive and early invasive disease according to cone depth: systematic review and meta-analysis. BMJ 2016;354:646-8.
5. Kyrgiou M, Valasoulis G, Stasinou SM, et al. Proportion of cervical excision for cervical intraepithelial neoplasia as a predictor of pregnancy outcomes. Int J Gynaecol Obstet 2015;128:141-7.

6. Castanon A, Landy R, Brocklehurst P, et al. Risk of preterm delivery with increasing depth of excision for cervical intraepithelial neoplasia in England: nested case-control study. BMJ 2014;349:g6223.

7. Liverani CA, Di Giuseppe J, Clemente N, et al. Length but not transverse diameter of the excision specimen for high-grade cervical intraepithelial neoplasia (CIN 2-3) is a predictor of pregnancy outcome. Eur J Cancer Prev 2016;25:416-22.

8. Miller ES, Grobman WA. The association between cervical excisional procedures, midtrimester cervical length, and preterm birth. Am J Obstet Gynecol 2014;211:242.e1-4.

9. Temming LA, Durst JK, Tuuli MG, et al. Universal cervical length screening: implementation and outcomes. Am J Obstet Gynecol 2016;214:523.e1-8.

10. Ortoft G, Henriksen T, Hansen E, et al. After conisation of the cervix, the perinatal mortality as a result of preterm delivery increases in subsequent pregnancy. BJOG 2010;117:258-67.

11. Reilly $\mathrm{R}$, Paranjothy $\mathrm{S}$, Beer $\mathrm{H}$, et al. Birth outcomes following treatment for precancerous changes to the cervix: a populationbased record linkage study. BJOG 2012;119:236-44.

12. Danhof NA, Kamphuis El, Limpens J, et al. The risk of preterm birth of treated versus untreated cervical intraepithelial neoplasia $(\mathrm{CIN})$ : a systematic review and meta-analysis. Eur J Obstet Gynecol Reprod Biol 2015;188:24-33.

13. Ueki M, Ueda M, Kurokawa A, et al. Cytologic study of the tissue repair cells of the uterine cervix. With special reference to their origin. Acta Cytol 1992;36:310-8.

14. Papoutsis D, Rodolakis A, Mesogitis S, et al. Regeneration of uterine cervix at 6 months after large loop excision of the transformation zone for cervical intraepithelial neoplasia. BJOG 2012;119:678-84.

15. Testa AC, Di Legge A, De Blasis I, et al. Imaging techniques for the evaluation of cervical cancer. Best Pract Res Clin Obstet Gynaecol 2014;28:741-68.

16. Bornstein J, Bentley J, Bösze P, et al. 2011 colposcopic terminology of the international federation for cervical pathology and colposcopy. Obstet Gynecol 2012;120:166-72.

17. Paraskevaidis E, Bilirakis E, Koliopoulos G, et al. Cervical regeneration after diathermy excision of cervical intraepithelial neoplasia as assessed by transvaginal sonography. Eur J Obstet Gynecol Reprod Biol 2002;102:88-91.

18. Nicolas F, Robert AL, Lavoué $\mathrm{V}$, et al. Ultrasound evaluation of cervical regeneration after LLETZ for cervical intraepithelial neoplasia: a prospective observational study. Anticancer Res 2014;34:3799-805

19. Papoutsis D, Daskalakis G, Antonakou A, et al. Sonographic measurement of cervical volume in nonpregnant women using the geometric formula for a cylinder versus the three-dimensional automated virtual organ computer-aided analysis (vocal). J Clin Ultrasound 2011;39:322-8.

20. Sasieni P, Castanon A, Landy R, et al. Risk of preterm birth following surgical treatment for cervical disease: executive summary of a recent symposium. BJOG 2016;123:1426-9.

21. Founta C, Arbyn M, Valasoulis G, et al. Proportion of excision and cervical healing after large loop excision of the transformation zone for cervical intraepithelial neoplasia. BJOG 2010;117:1468-74.

22. Phadnis SV, Atilade A, Young MP, et al. The volume perspective: a comparison of two excisional treatments for cervical intraepithelial neoplasia (laser versus LLETZ). BJOG 2010;117:615-9.

23. Martens JE, Smedts FM, Ploeger D, et al. Distribution pattern and marker profile show two subpopulations of reserve cells in the endocervical canal. Int J Gynecol Pathol 2009;28:381-8.

24. Arbyn M, Kyrgiou M, Simoens C, et al. Perinatal mortality and other severe adverse pregnancy outcomes associated with treatment of cervical intraepithelial neoplasia: meta-analysis. BMJ 2008;337:a1284.

25. Khalid S, Dimitriou E, Conroy R, et al. The thickness and volume of LLETZ specimens can predict the relative risk of pregnancy-related morbidity. BJOG 2012;119:685-91.

26. Noehr B, Jensen A, Frederiksen K, et al. Depth of cervical cone removed by loop electrosurgical excision procedure and subsequent risk of spontaneous preterm delivery. Obstet Gynecol 2009;114:1232-8. 